\title{
Interaction Law between Natural Fractures-Vugs and Acid-Etched Fracture during Steering Acid Fracturing in Carbonate Reservoirs
}

\author{
Yifan Dai $\mathbb{D}^{1,2}$ Bing Hou $\mathbb{D}^{1,2}$ Changlin Zhou, ${ }^{3}$ Kunpeng Zhang, ${ }^{1,2}$ and Fei Liu ${ }^{3}$ \\ ${ }^{1}$ State Key Laboratory of Petroleum Resources and Prospecting, China University of Petroleum, Beijing, China \\ ${ }^{2}$ MOE Key Laboratory of Petroleum Engineering, China University of Petroleum, Beijing, China \\ ${ }^{3}$ Engineering Technology Research Institute, PetroChina Southwest Oil \& Gas Field Company, Chengdu 610017, China
}

Correspondence should be addressed to Bing Hou; binghou@vip.163.com

Received 4 November 2020; Revised 7 January 2021; Accepted 23 March 2021; Published 16 April 2021

Academic Editor: Tivadar M. Tóth

Copyright $\odot 2021$ Yifan Dai et al. This is an open access article distributed under the Creative Commons Attribution License, which permits unrestricted use, distribution, and reproduction in any medium, provided the original work is properly cited.

\begin{abstract}
Steering acid fracturing is a technique that improves the conductivity of carbonate reservoir. It is widely used in a carbonate reservoir. However, due to the lack of comparative experiments, the application of steering acid to improve the fracturing results is still unknown. Therefore, a series of true triaxial acid fracturing experiments were conducted to study steering acid fracturing in carbonate reservoir. The carbonate specimens used in the experiment were from the Qixia group and Dengsi Member in Sichuan, China. In this study, slick water, cross-linked gel, and self-generating acid were used as ahead fluid to cooperate with steering acid. Experimental results show that (1) the low-viscosity ahead fluid with steering acid can result in more complex fractures; (2) the complexity of fractures is influenced by natural fracture and the viscosity of the ahead fluid; and (3) based on the $3 \mathrm{D}$ scanning results of the fracture surface, different ahead fluids will lead to different corrosion results. This study provides useful suggestions on steering acid fracturing design and physical simulation experiments.
\end{abstract}

\section{Introduction}

Various development techniques applied to unconventional reservoirs such as low-permeability reservoirs have received increasing attention [1-5]. Carbonate reservoirs have lower permeability and porosity as compared to conventional reservoirs, which results in challenges for the conventional development methods [6]. Because the carbonate content in these reservoirs is high and it is easy to react with the acid, the acid fracturing operation is usually used to stimulate the carbonate reservoir to improve permeability and porosity. However, compared with normal hydraulic fracturing, it is hard to control the penetration distance caused by acid solution in acid fracturing. The difficulty of acid fracturing treatment is the leak off of acid which hampers the acidetched fractures to propagate and reduces the effective acid penetration distance [7]. Therefore, it is necessary to design some specific experiments that help to solve this problem. For example, Wang et al. showed that self-generating acid is highly compatible with gelled acid and self-diverting acid, which suggests that self-generating acid can be used as the ahead fluid in the experiment [4]. Hou et al. reported a successful utilization of alternating acid fracturing, which used self-generating acid as the ahead fluid to penetrate and cool reservoir and gelled acid to deeply penetrate carbonate reservoir (FAN, et al. 2018). These studies provide a reference for experiment design. Hou et al. introduced an innovative method to realize the acid fracturing experiment based on true triaxial experiment for the first time [8]. The study provides a way to digitally process experimental results.

However, there are many problems when applying conventional experimental methods to steering acid experiments. Steering acid has the advantages of low damage to reservoir and simple construction process. The initial viscosity of steering acid is low, but the viscosity will gradually increase as the acid reacts with rocks. After the acid is injected into the reservoir, it will first react with the carbonate rocks, and then, the viscosity will gradually increase as the reaction proceeds. It will have the large plugging strength, forcing the subsequent working fluid to turn to the low-permeability reservoir. Moreover, as the fracture propagates, the acid viscosity of the front end rises, affecting fracture propagation, which results 


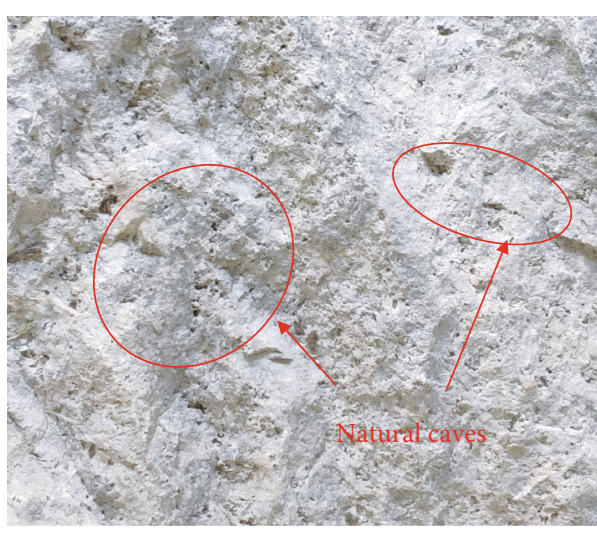

(a)

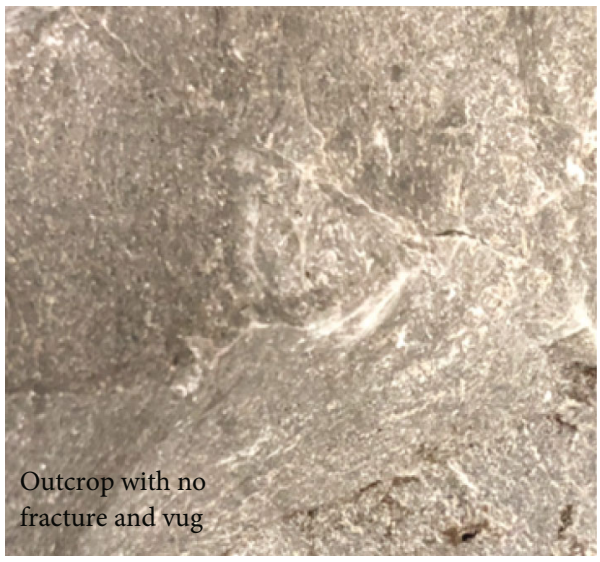

(b)

FIgURE 1: Carbonate outcrop: (a) fracture-vug carbonate; (b) matrix-type carbonate.

TABLE 1: Physical properties of experimental specimen.

\begin{tabular}{lccc}
\hline Property & Fracture-vug carbonate rock & Matrix-type carbonate rock & Unit \\
\hline Modulus of elasticity & 33 & 35 & $\mathrm{GPa}$ \\
Poisson's ratio & 0.2 & 0.2 & - \\
Porosity & 3.1 & 2.8 & 0.1 \\
Permeability & 0.1 & 103.78 & $\mathrm{mD}$ \\
Compressive strength & 102.01 & 1.1 & $\mathrm{MPa}$ \\
Reservoir pressure coefficient & 1.1 & $14-15$ & - \\
Coefficient of in situ stress difference & $14-15$ & $\%$ \\
\hline
\end{tabular}

in complex fracture networks. Thus, the large-scale triaxial experiments are required to study steering acid fracturing because the steering acid needs a sufficient fracture surface area to complete chemical reaction. In addition, there are many challenges for large-scale experiments, such as the leak off of acid, high treatment pressure, high fracture tortuosity, and occurrence of multiple fractures. However, currently, there is little research about steering acid fracturing, and the understanding of how to apply steering acid to hydraulic fracturing needs to be improved.

In this paper, the experimental method of simulating the laboratory injection stimulation was improved. Different kinds of ahead fluid were used with the steering acid to acidify and fracture the rock outcrop specimens of different reservoirs. The pump pressure curve during fracturing and the fracture surface after fracturing were analyzed, so that the influences of the steering acid in different periods of fracturing can be understood. The different conditions to apply steering acid were summarized. In one word, the study results can be used to help improve steering acid fracturing design.

\section{Methodology}

2.1. Experimental Specimen. The outcrops used in the experiment were from the Qixia group and Dengsi Member in Sichuan, China. Fracture-vug carbonate rocks from the Qixia group were used in experiment \#1, \#3, and \#4, which involve many natural fractures and vugs in the rock, as shown in Figure 1(a). Matrix-type carbonate rock from the Dengsi
Member was used in experiment \#2, which is characterized by weak heterogeneity and less cracks and vugs, as shown in Figure 1(b).

The physical parameters of experimental specimen are illustrated in Table 1.

Outcrops were selected based on the integrity and distribution of natural fractures. All specimens were cut into 300 $\times 300 \times 300 \mathrm{~mm}$ cubes. The specimens were drilled by an impact-resistant bench drill to create a hole with a length of $170 \mathrm{~mm}$ and a diameter of $14 \mathrm{~mm}$, which is used to simulate a borehole. The size of the wellbore is shown in Figure 2(a). It is $120 \mathrm{~mm}$ long and fixed in the hole using a special glue with high strength and good sealing performance. The bottom of the wellbore was prefilled with a $50 \mathrm{~mm}$ long highpermeability foam filler to simulate the openhole completion. The overall rock specimen is shown in Figure 2(b).

2.2. Experimental Fluid. The steering acid (Figure 3) has the advantages of low damage to the reservoir and simple operation process. The initial viscosity of the steering acid is low, but the viscosity will gradually increase after it is injected into the reservoir [9]. The mechanism of this phenomenon is that the acid will react with the carbonate in rocks.

Slick water (Figure 4(a)) is a kind of low-viscosity fracturing fluid. Gel (Figure 4(b)) is a kind of high-viscosity fracturing fluid. Self-generating acid (Figure 4(c)) is a fracturing fluid used in ordinary acid fracturing. For slick water, its special properties such as particularly low viscosity and ability to generate complex fracture network in the shale reservoir have 


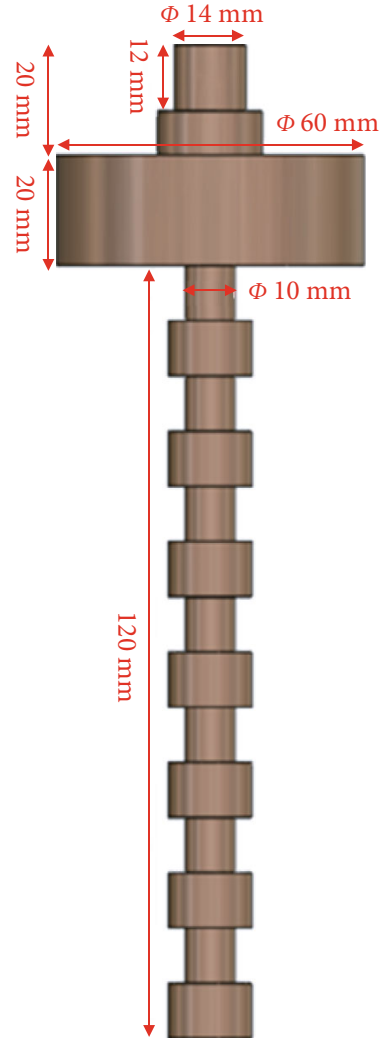

(a)

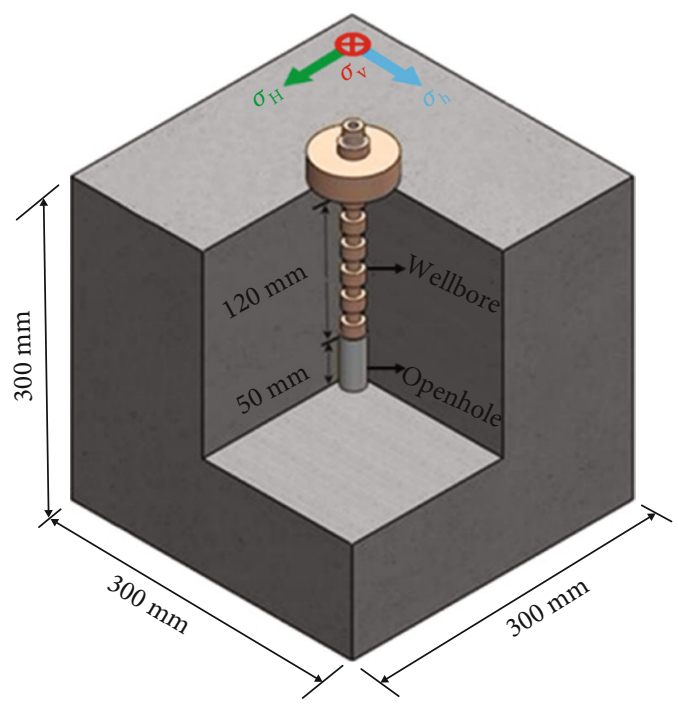

(b)

Figure 2: Experimental specimen schematic: (a) wellbore; (b) experimental specimen. The parameters are shown in the figure. The wellbore is $120 \mathrm{~mm}$ long and is fixed in the hole using a special glue with high strength and sealing performance.

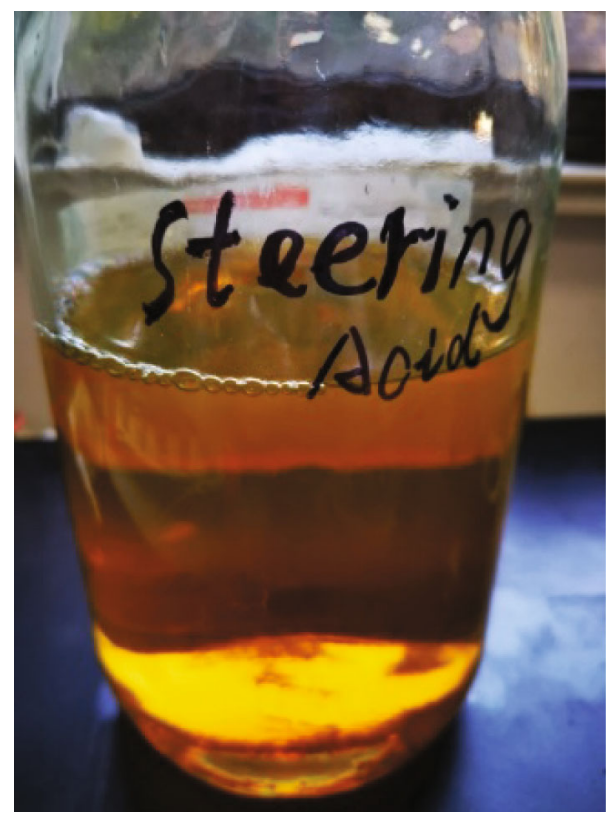

Figure 3: Steering acid.

been extensively studied [10]. Although vugs and natural fractures in carbonate reservoirs might lead to the loss of slick water, slick water still can be used in the acid fracturing treatment as ahead fluid. For gel, it is widely used in shale hydrau- lic fracturing. For acid fracturing, the gel can reduce the leak off of acid [2]. For self-generating acid, it is widely used in acid fracturing. Although its acidity in the beginning is not obvious, acid-generating salt will form HCL by hydrolysis reaction when it is injected into the wellbore. When injecting self-generating acid into the reservoir, the acid will corrode the formation and reduce rock fracture pressure. Tracer was added into the experimental fluid to mark the fracture surface clearly and accurately.

The parameters and formula of experimental fluid are illustrated in Table 2.

2.3. Experimental Apparatus. The process of acid fracturing is simulated by true triaxial simulation experiment system. The experimental system consists of the following components: a high pressure alternating injection system (Figure 5(a)), a triaxial pressure loading system (Figure 5(b)), and a data collection system (Figure 5(c)).

The alternating injection system performs hydraulic fracturing by pumping the fracturing fluid into the wellbore. The triaxial pressure loading system can independently load the specimen in three different directions. The data processing system can display four pressures: $x$-axis pressure, $y$-axis pressure, $z$-axis pressure, and injection pressure. All experimental devices are resistant to acid and pressure.

2.4. Experimental Scheme. When horizontal stress difference is relatively low, the fracture morphology is complex because 


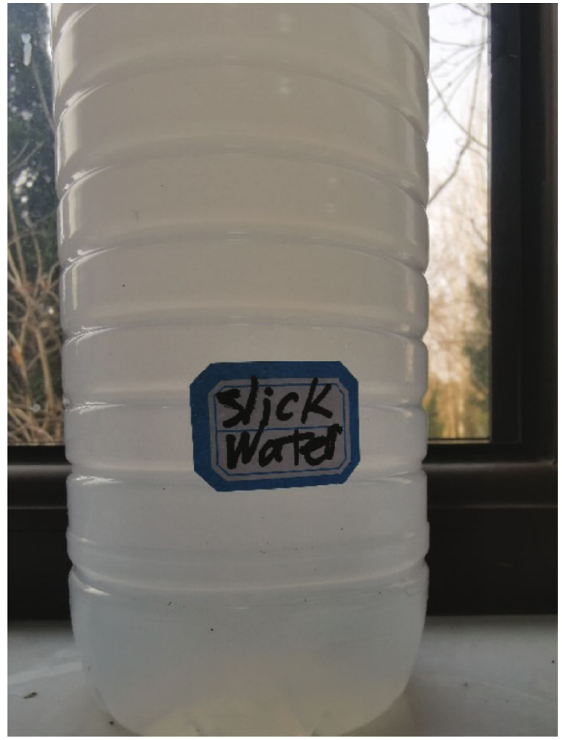

(a)

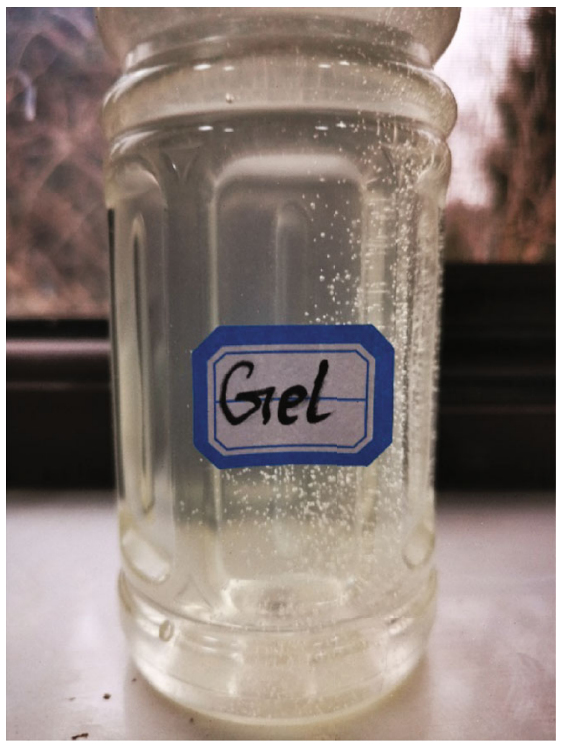

(b)

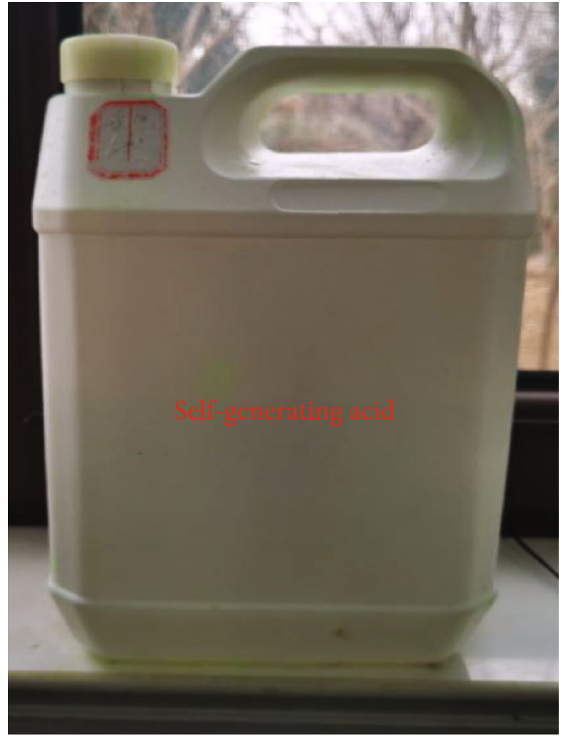

(c)

FIGURE 4: Experimental fluid: (a) slick water; (b) gel; (c) self-generating acid.

it is mainly controlled by natural fractures. In addition, the large vertical stress will reduce fracture pressure ([11]). However, the minimum horizontal stress has to be large enough to eliminate the Poisson effect. Since the size of the specimen is relatively small, the pump rate should be low to ensure that the acid can fully react with carbonate. Hence, all experiments are conducted with a vertical stress of $25 \mathrm{MPa}$, maximum horizontal principal stress of $20 \mathrm{MPa}$, minimum horizontal principal stress of $10 \mathrm{MPa}$, and a pump rate of $10 \mathrm{~mL} / \mathrm{min}$.

Note that various fracturing fluids were used in the experiment to mix with the steering acid, so the experimental scheme was designed with reference to the alternating injection experiments previously [12].

The experimental scheme is illustrated in Table 3.

\section{Experimental Results and Analysis}

\subsection{Experimental Results}

\subsubsection{Distribution of Natural Fractures before Fracturing.} Natural fractures were roughly marked before the experiment. The distribution of natural fractures in experiment $\# 1$ is shown in Figure 6(a). There was a natural fracture about $15 \mathrm{~cm}$ away from the wellbore on the rock specimen. The angle between the fracture and the wellbore was about $30^{\circ}$, and the fracture extended to the center of the specimen. The distribution of natural fractures in experiment \#2 is shown in Figure 6(b). There was a natural fracture about $15 \mathrm{~cm}$ away from the wellbore. The angle between the fracture and the wellbore was about $70^{\circ}$, and the fracture extends to the center of the specimen. The distribution of natural fractures in experiment \#3 is shown in Figure 6(c). There was a natural fracture about $10 \mathrm{~cm}$ from the wellbore, which was parallel to the wellbore and extended from the upper surface of the rock specimen to the lower surface. The distribu- tion of natural fractures in experiment \#4 is shown in Figure $6(\mathrm{~d})$. There was a natural fracture about $15 \mathrm{~cm}$ from the wellbore, which was perpendicular to the wellbore.

3.1.2. Analysis of Experimental Pressure. The treatment pressure curves are shown in Figure 7 . The pump rate is maintained at $10 \mathrm{~mL} / \mathrm{min}$. The pressure profiles of experiment $\# 1$, \#2, \#3, and \#4 are compared. It is found that the viscosity of the fracturing fluid is related to the fracture initiation pressure. The fracture pressure varies as ahead fluid changes. Note that points a, b, c, and d represent fracture initiation pressures.

The sharp drop of treatment pressure represents fracture initiation. The curve of experiment \#1 is analyzed. Fracture initiation pressure is reached at point a. In the early stage of fracturing, the injection pump was out of order and acid pumping was stopped. The pump pressure slowly decreased. It indicates that the acid was seeping into the rock mass. There is only one single peak on the pump pressure curve, suggesting that the rock only experienced one significant rupture.

In experiment \#2, pressure dropped sharply after point $b$. There is only one single peak on the pump pressure curve, indicating that the there is only one main rupture in the rock. There are pressure fluctuations at the end of fracturing, suggesting that there are several peaks during the experiment. After the fracture propagates thorough the specimen, the pressure drops sharply.

In experiment \#3, the treatment pressure curve shows the fracture has interactions with the natural fractures and vugs. After fracture initiation pressure is reached at point $c$, the pressure fluctuates sharply. It is probably because many small-scale fractures formed after the rock mass cracked.

In experiment \#4, there is less pressure fluctuation, as compared to experimental \#3. Before the rock specimen 


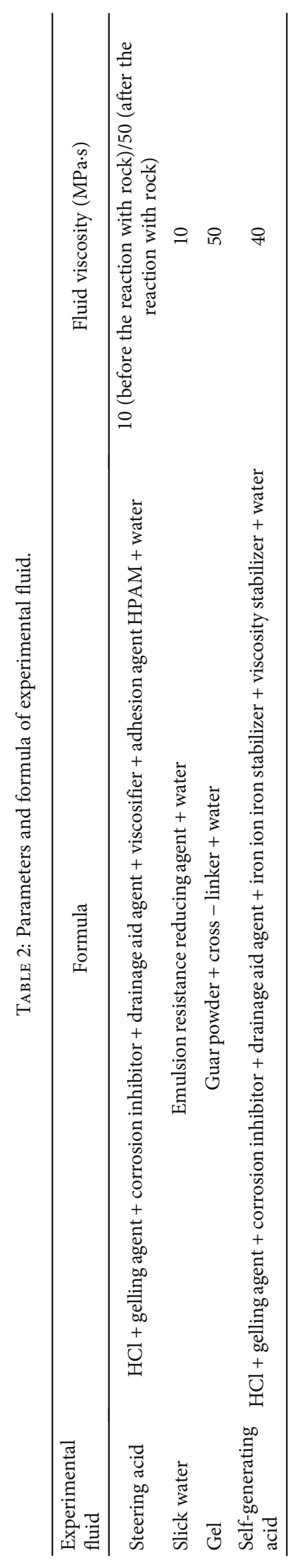




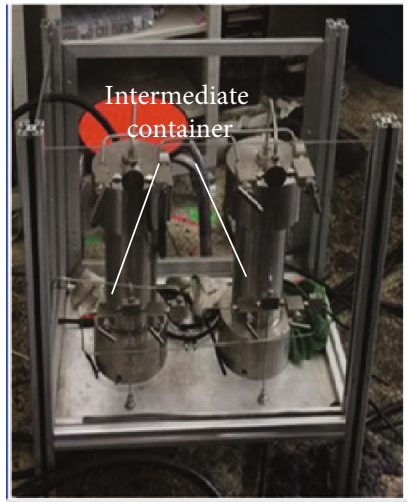

(a)

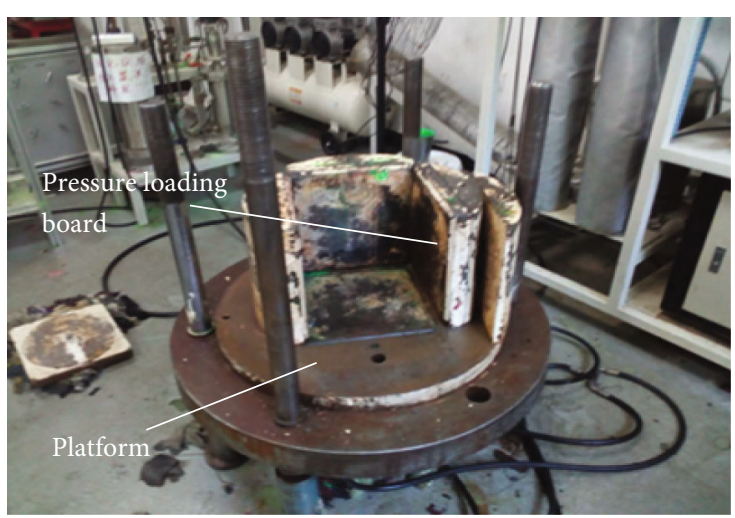

(b)

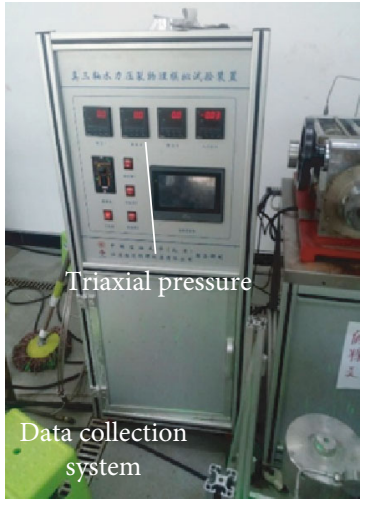

(c)

FIGURE 5: Experimental apparatus: (a) alternating injection system; (b) triaxial pressure loading system; (c) data collection system. High pressure alternating injection system can change fracturing fluid at any time during injection. The triaxial pressure loading system can load the pressure on the surface of the specimen by hydraulic driving. The data collection system records the pressure values per second.

TABLE 3: Experimental scheme for the steering acid fracturing experiments.

\begin{tabular}{lcccc}
\hline \multirow{2}{*}{ Experiment number } & Rock type & $\begin{array}{c}\text { Triaxial stress }(\mathrm{MPa}) \\
\sigma_{\mathrm{v}} / \sigma_{\mathrm{H}} / \sigma_{\mathrm{h}}\end{array}$ & Pump rate $(\mathrm{mL} / \mathrm{min})$ & Experimental fluid \\
\hline$\# 1$ & Fracture-vug carbonate rock & $25 / 20 / 10$ & 10 & Steering acid \\
$\# 2$ & Matrix-type carbonate rock & $25 / 20 / 10$ & 10 & Slick water + steering acid \\
$\# 3$ & Fracture-vug carbonate rock & $25 / 20 / 10$ & 10 & Gel + steering acid \\
$\# 4$ & Fracture-vug carbonate rock & $25 / 20 / 10$ & 10 & Self - generating acid + steering acid \\
\hline
\end{tabular}

fractured, the pressure was maintained at around $25 \mathrm{MPa}$ with small fluctuations. It suggests that the ahead fluid was slowly reacting with the rock.

\subsubsection{Analysis of Experimental Results. The results of experi-} ment \#1 are shown in Figure 8. The direction of fracture is indicated by the yellow arrows. Near the bottom of the well, the acid seeped into the interior of the rock mass. After the acid flew through the area, a clearly identifiable group of dissolution vugs is formed in a multilevel dendritic shape. The main acid-etched fracture was first parallel to the direction of the maximum horizontal principal stress. After a certain distance, it intersected with the natural fracture and then turned into the direction of the natural fracture. As a consequence, a secondary fracture on the surface of the natural fracture was formed. Then, an acid fracturing turning step occurred in which the fracture turned at the continuous vugs. Subsequently, the fracture turned to the maximum horizontal principal stress direction and continued to propagate.

The results of experiment \#2 are shown in Figure 9. The main fracture propagated in the direction of the maximum horizontal principal stress. On the surface of main acidetched fracture, there was an acid-etched black deep groove near the wellbore. In addition, there was another acid-etched fracture at the rear end of the main fracture. The fracture was perpendicular to the main fracture. The acid-etching phenomenon and a complex fracture network structure is obvious.

The results of experiment \#3 are shown in Figure 10. There was a two-wing vertical fracture that propagated along the direction of the maximum horizontal principal stress. One side propagated to the natural fracture and had an interaction with natural fracture, which eventually opened the natural fracture. The other side propagated almost in a straight line without a significant turning. After opening the rock, it was observed that the surface area of acid-etched fracture is large and the acid etching is obvious.

The results of experiment \#4 are shown in Figure 11. The fracture propagated in the direction of the maximum horizontal principal stress. One side propagated to the boundary of the specimen and the other side changed direction after a certain distance. At the bottom of the wellbore, the acidetched fracture intersected with and propagated along the natural fracture. The fracture surface was obviously etched.

\subsection{Influence of Ahead Fluid on Acid Fracturing. The simple} schematic diagrams of the experimental results are shown in Figure 12.

According to the results of experiment \#1, it was not satisfactory when steering acid was injected directly into the reservoir for acid fracturing. This result was consistent with previous research [13]. This was mainly because the subsequent acid solution would be prevented from flowing into the small fractures in the formation after the acid viscosity increased. The reaction range of the acid solution was small, and the effect was poor. Therefore, it was necessary to inject a certain amount of ahead fluid to mix with the steering acid. Note that the compatibility between ahead fluid and steering acid was significant for the effect of the acid fracturing. Thus, 

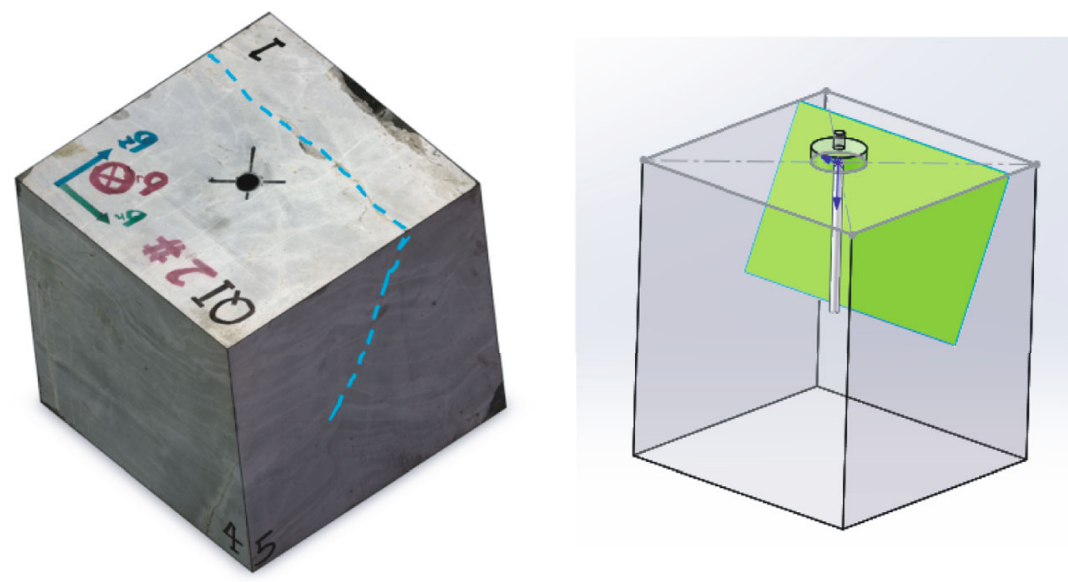

(a)
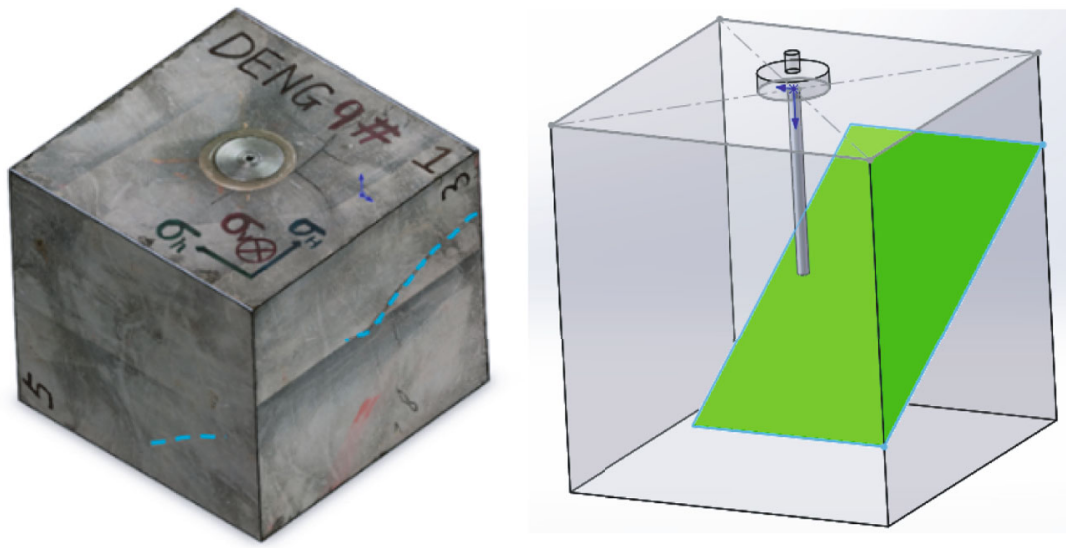

(b)
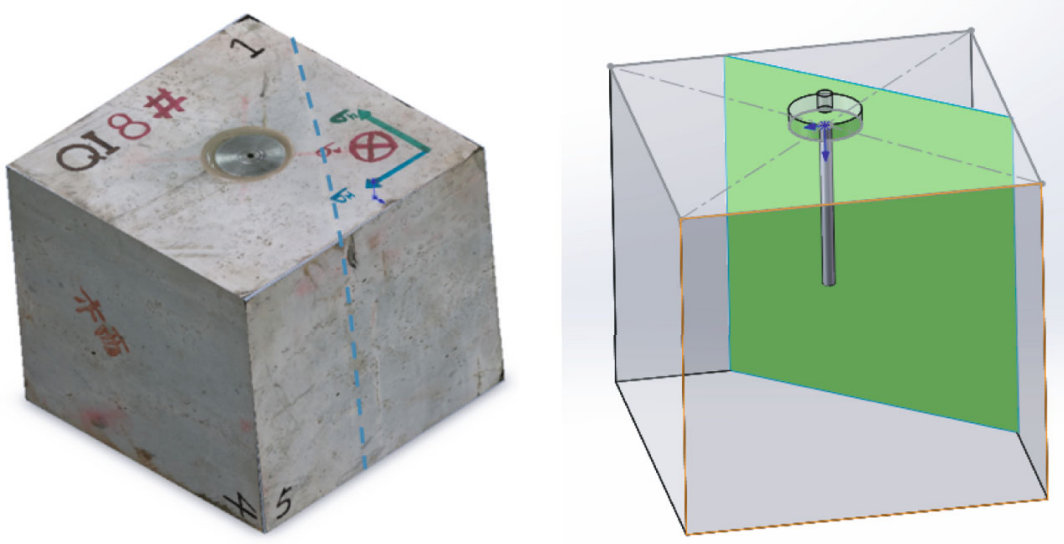

(c)

Figure 6: Continued. 

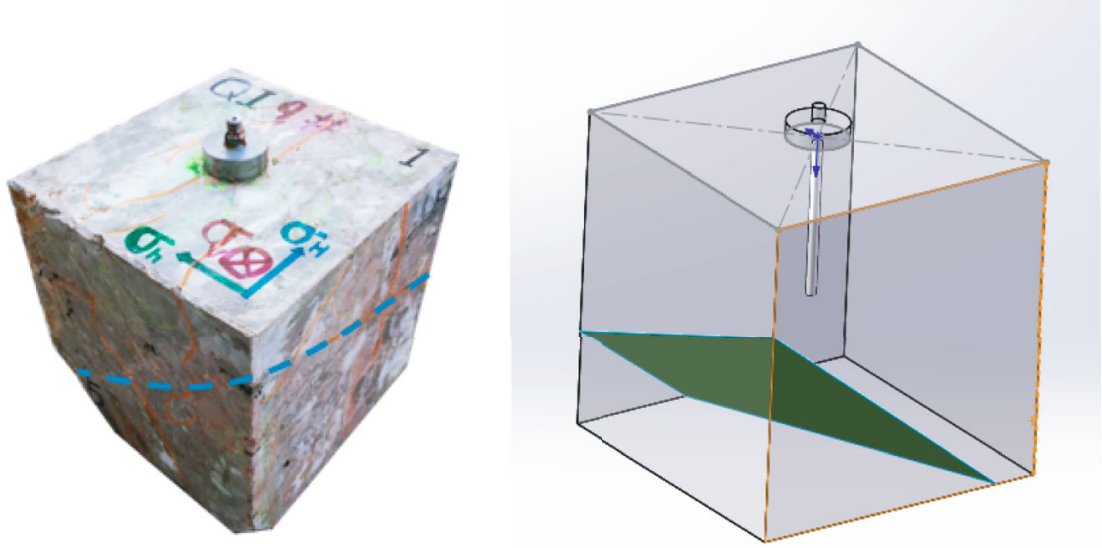

(d)

FIGURE 6: Rock specimen before experiment: (a) specimen 1; (b) specimen 2; (c) specimen 3; (d) specimen 4 . The picture on the left of each group is the specimen photo, and the picture on the right is a perspective view picture.

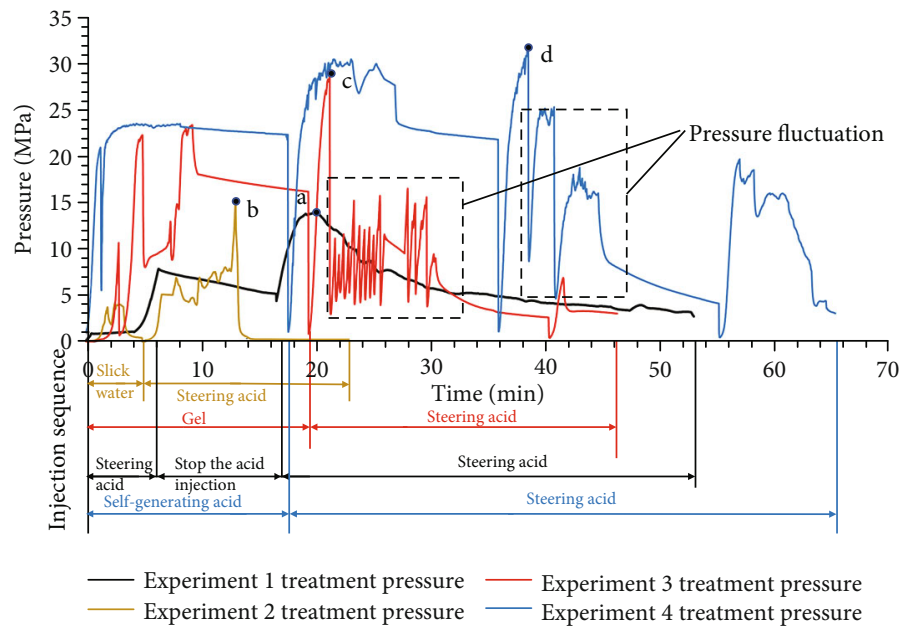

FiguRE 7: Experimental treatment pressure curve (four experiments were carried out under the same triaxial pressure and pump rate.)

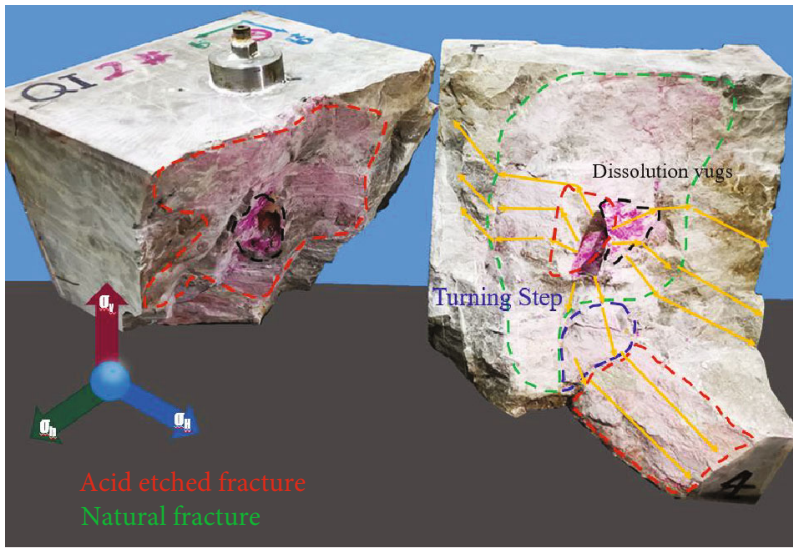

Figure 8: Results of experiment 1. The direction of fracture is indicated by the yellow arrows. The acid-etched fractures are marked by red circle. The natural fractures are marked by green circle. different experiments were conducted, with the same in situ stress conditions and pump rate. Three kinds of ahead fluid were used to mix with the steering acid. The results are shown in Table 4.

Based on experiment \#2, when the low-viscosity slick water was used as the ahead fluid for acid fracturing, an obvious fracture diversion was found in the rock, and the fracture network was complicated. However, for experiment \#3, when the high-viscosity gel was used as the ahead fluid for acid fracturing, there was no obvious turning step. The acidetched fracture would directly connect to the natural fracture. The fracture geometry is mainly affected by natural fracture, and the fracture complexity of experiment \#3 was low. Selfgenerating acid can corrode carbonate reservoirs. Thus, when self-generating acid was used as ahead fluid, the acid-etched phenomenon of rock specimen was the most significant. There were two fractures on both sides of the specimen in experiment \#4. One side propagated as a straight line, and the other side has a diversion. The acid-etched fractures on both sides connected to the natural fracture. Although the 


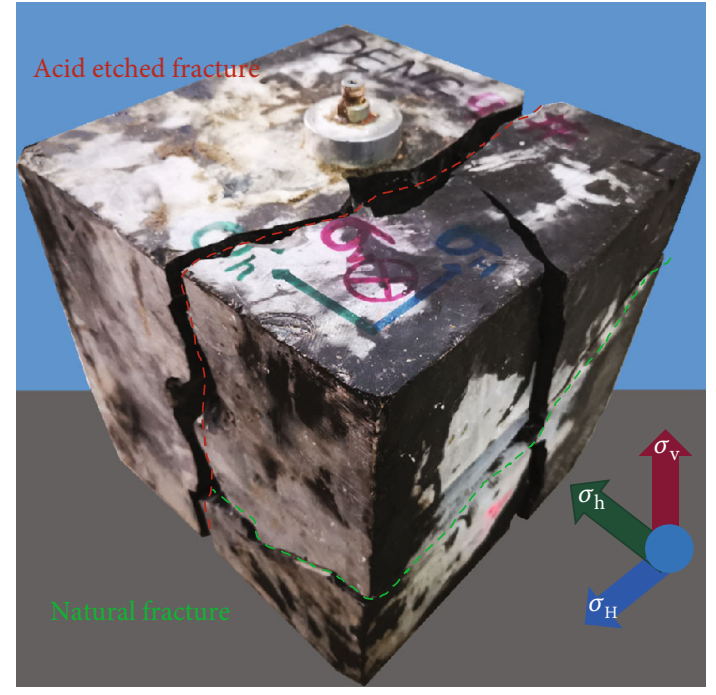

(a)

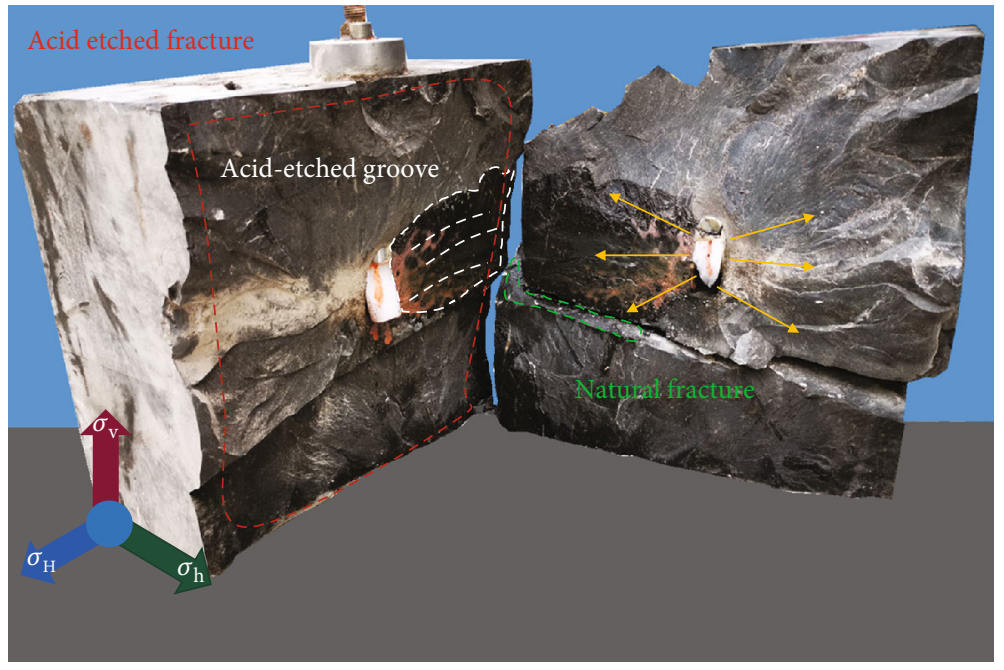

(b)

FIGURE 9: Results of experiment 2: (a) external view; (b) internal view. The acid-etched groove is obvious, and the fracture complexity is high.

fracture complexity was not significant, the acid-etching phenomenon was the most obvious.

The most complex fracture network forms when the lowviscosity ahead fluid was mixed with the steering acid. This is mainly due to the fact that as steering acid reacts with the rock, the viscosity of the fluid rises, causing fracture diversion. If the viscosity of ahead fluid is high, the fracture propagation direction will mainly be controlled by the ahead fluid; the effect of the steering acid is not significant. In the meantime, ahead fluid, due to its high viscosity, can flow into main acid fracture and main natural fracture, but it is not easy for the ahead fluid to enter the small fractures. Therefore, only one secondary fracture is formed. Thus, the fracture complexity is low. Based on the experimental results and analysis, it is recommended to use slick water as the ahead fluid.

\subsection{Influence of Natural Fractures and Vugs on Acid} Fracturing. In carbonate reservoir, it is common to observe vugs and fractures. The interaction between artificial fractures and natural fractures has been widely studied [14]. However, there are few studies on the influence of natural fractures and vugs on acid fracturing. In the process of steering acid fracturing of carbonate formations, the distribution of natural fractures and vugs is related to the final fracture complexity ([15].). From the results of the comparative experiment, the influence of natural fractures and vugs on fracturing can be observed. In experiment \#2, matrix-type carbonate rock was used, which had less fractures and vugs as compared to fracture-vug carbonate rock. However, experimental results show a secondary fracture still formed in different direction at the rear end of the main fracture. In experiment \#3, a different experimental fluid was used on fracture-vug carbonate rock. The gel created a main fracture during fracturing process. The main fracture did not change direction until the natural fracture was reached, and there was no turning step. It can be observed that natural fractures and vugs affect the propagation direction of fractures during acid fracturing. Compared with the viscosity of the ahead fluid, natural fractures and vugs have less effect on the fracturing. In one word, the major factor of forming complex fractures is the viscosity of the ahead fluid.

In order to eliminate the effect of ahead fluid, fracturevug carbonate rock and steering acid were used during experiment \#1. Small vugs are observed randomly distributed inside the fracture-vug carbonate rock. The experimental results are shown in Figure 13. There are continuous vugs near the bottom of the well. At the beginning, acid fractures propagated along the direction of maximum horizontal principal stress. When it touched the continuous vugs, it changes propagation direction immediately and propagated along the direction of vugs. Thus, a turn was observed to occur at the continuous vugs, resulting in an acid fracturing turning step. In one word, when the steering acid was used alone for acid fracturing, it was easy to change the direction of fractures under the influence of vugs or natural fractures.

In order to observe the effect of natural vugs on fracturing fluid, a tracer was added in the experimental fluid. The results of experiment \#3 demonstrate a low fracture complexity, so that it is highly possible that natural vugs have a significant influence on the fracturing fluid. In experiment \#3, the natural vugs in the rock specimen were distributed in two strips. After the rock specimen was broken, the fracture surface was observed to propagate along the direction of the maximum horizontal principal stress. Also, there were two clear vug strips on the fracture surface. The results of experiment \#3 after the fracturing are shown in Figure 14. The surface of vugs was dyed fluorescent green, because the fracturing fluid traveled mostly along the vug strips and the acid reacts with the vugs during the fracturing.

When acid fluid entered vugs, the pressure would reduce drastically, due to the instantaneous expansion of volume. Simultaneously, the acid reacted with the rock surface, and the volume would be further enlarged. As more subsequent fluid was pumped in, the pressure rose. Therefore, pressure fluctuations were observed on the pressure curve (Figure 15). 


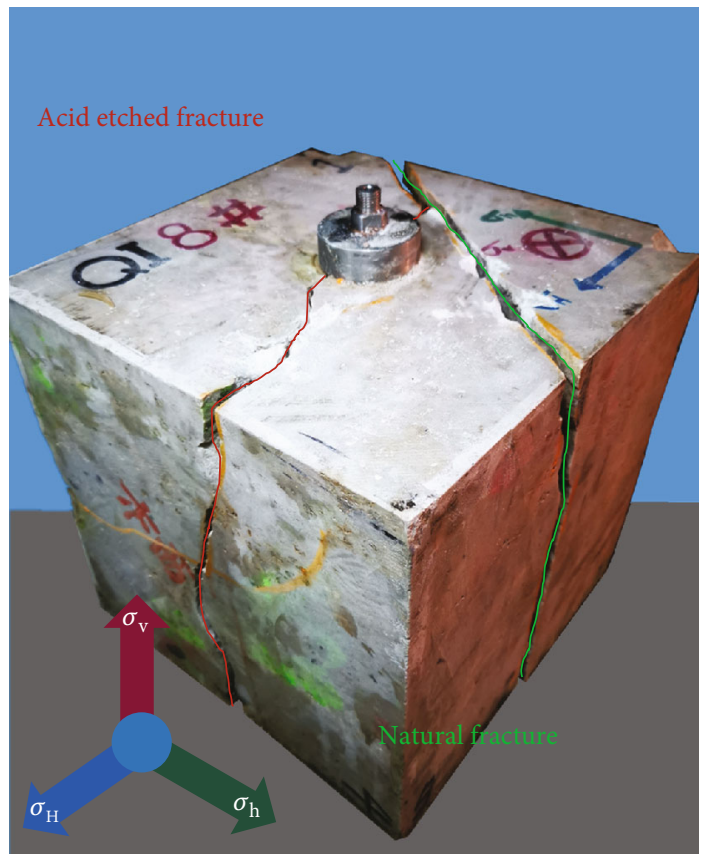

(a)

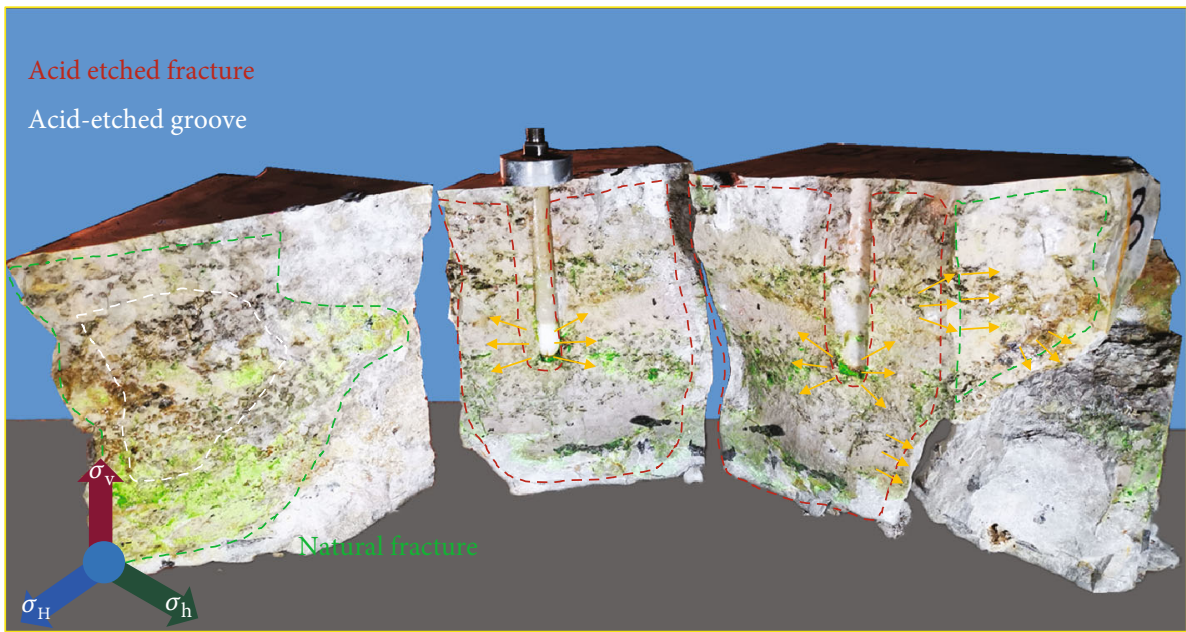

(b)

Figure 10: Results of experiment 3: (a) external view; (b) internal view. The acid-etched groove is obvious, and the fracture complexity is low.

It can be concluded that when the steering acid does not mix with ahead fluid, it is easy for acid fracture to change direction under the influence of natural fractures and vugs. This is mainly because when the acid meets the fractures or vugs, the surface area of the acid and rock contact increases rapidly, the reaction is accelerated, and the viscosity increased rapidly. Eventually, the direction of fracture propagation changes. If the steering acid mixes with ahead fluid, the complexity of fractures is affected by natural fractures and viscosity of the ahead fluid. Generally, for rocks with more vugs, the leak-off rate of fracturing fluid will be larger.

3.4. Influence of Steering Acid on Fracture Surface. During acid fracturing, the acid will corrode the carbonate reservoir, which is macroscopically evidenced based on the roughness of the fracture surface. Previous studies have revealed that the roughness of the fracture surface is positively correlated with the conductivity (Rashnur M, et al. 2019). The higher the roughness, the higher the fluid conductivity. The absolute value of the Gaussian curvature can be used to characterize the roughness of the surface, which actually provides the degree of surface curvature. When the Gaussian curvature of the surface changes fast, it indicates that the internal variation of the surface is large, and thus, the roughness of the surface is higher.

Take experiment \#1 as an example. The fracture surface is shown in Figure 16(a). The 3D image of fracture surface (Figure 16(b)) was scanned by 3D scanning technology.

The area near the bottom of the well was selected. The Gaussian curvature of each point on the area was calculated, as shown in Figure 17. In order to display the relative size of Gaussian curvature, different colors were used to mark, red 


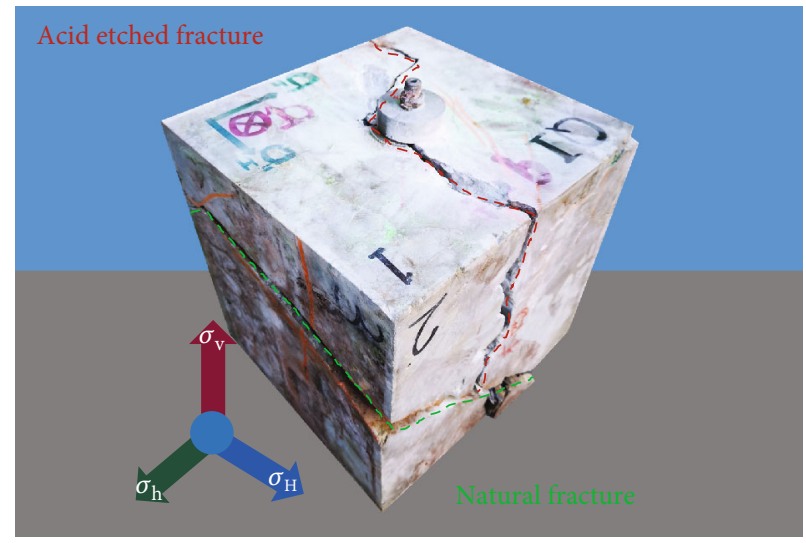

(a)

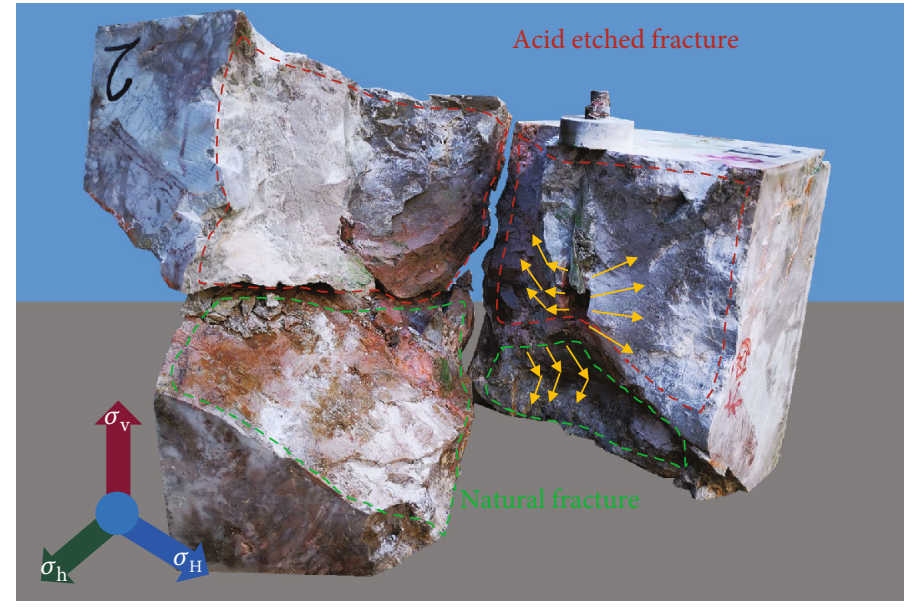

(b)

FIGURE 11: Results of experiment 4: (a) external view; (b) internal view. The change in the direction of fracture is not obvious. Fracture complexity is between experiment 2 and experiment 3.

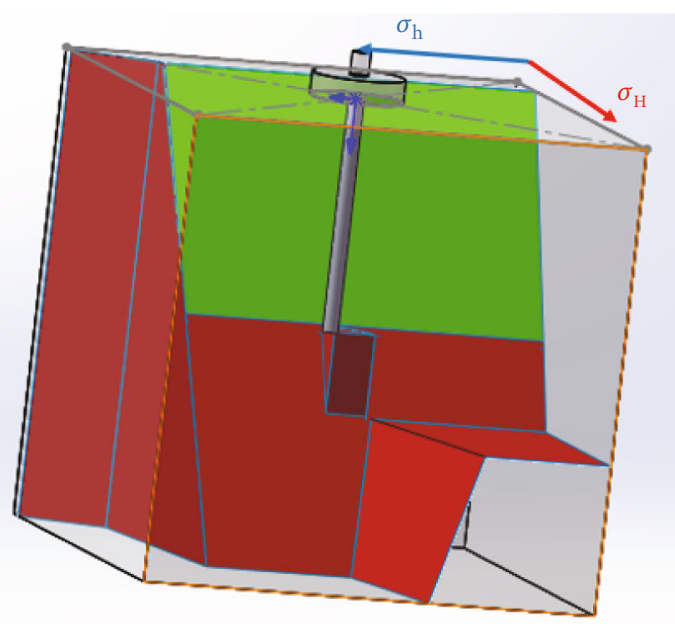

(a)

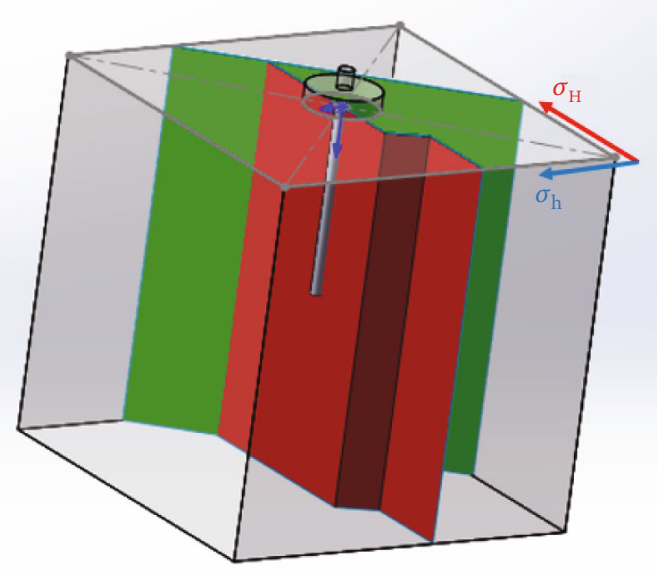

(c)

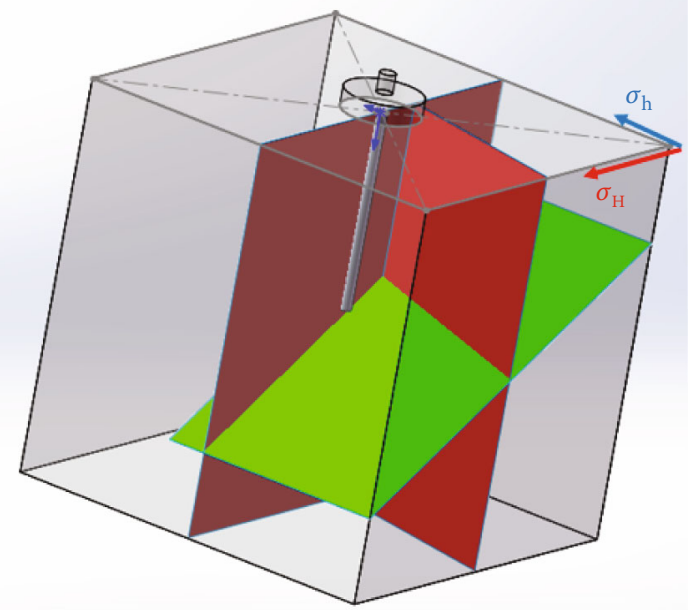

(b)

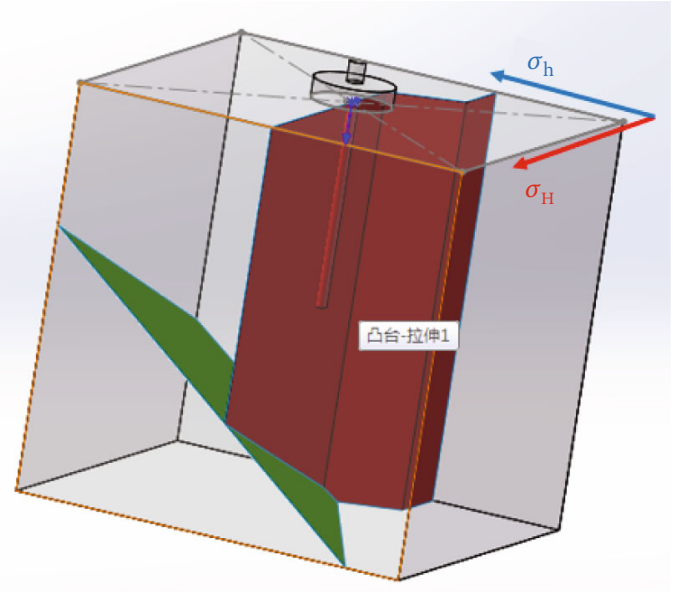

(d)

Figure 12: Perspective view of the distribution of fractures: (a) experiment 1; (b) experiment 2; (c) experiment 3; (d) experiment 4. Green surfaces indicate natural fractures, and red surfaces indicate acid-etched fractures. 
TABLE 4: Results of comparative experiments with different ahead fluid.

\begin{tabular}{|c|c|c|c|c|c|}
\hline Experiment & $\begin{array}{c}\text { Tri-axial } \\
\text { pressure } \\
(\mathrm{MPa}) \\
\sigma_{\mathrm{v}} / \sigma_{\mathrm{H}} / \sigma_{\mathrm{h}}\end{array}$ & Experimental fluid & $\begin{array}{c}\text { Degree of } \\
\text { fracture } \\
\text { diversion }\end{array}$ & $\begin{array}{l}\text { Relationship between hydraulic } \\
\text { fracture and natural fracture }\end{array}$ & $\begin{array}{l}\text { Fracture } \\
\text { complexity }\end{array}$ \\
\hline 2 & $25 / 20 / 10$ & Slick water + steering acid & High & Crossing & High \\
\hline 3 & $25 / 20 / 10$ & Gel + steering acid & Low & Diversion & Low \\
\hline 4 & $25 / 20 / 10$ & Self - generating acid + steering acid & High & Diversion & Medium \\
\hline
\end{tabular}
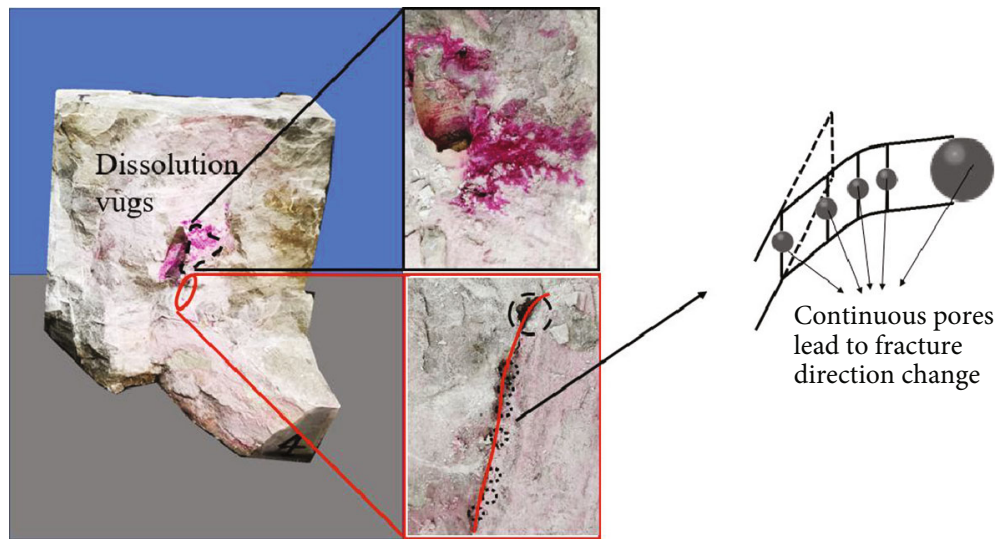

Figure 13: Continuous vug structure in experiment 1. There are continuous vugs on acid fracturing turning step.

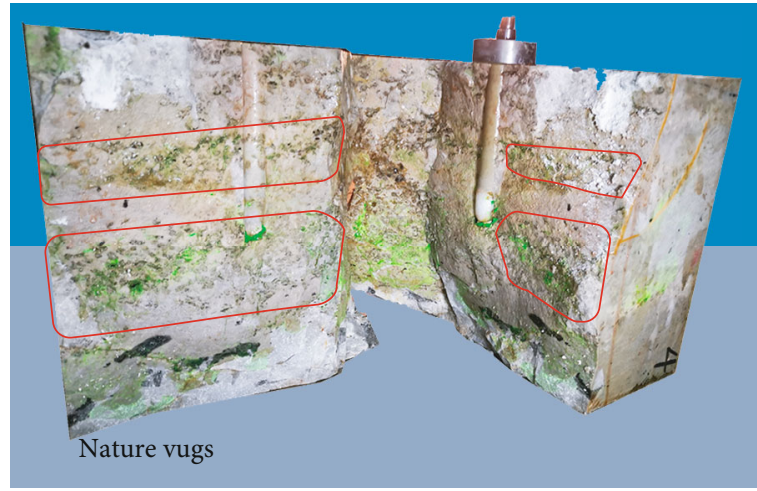

(a)

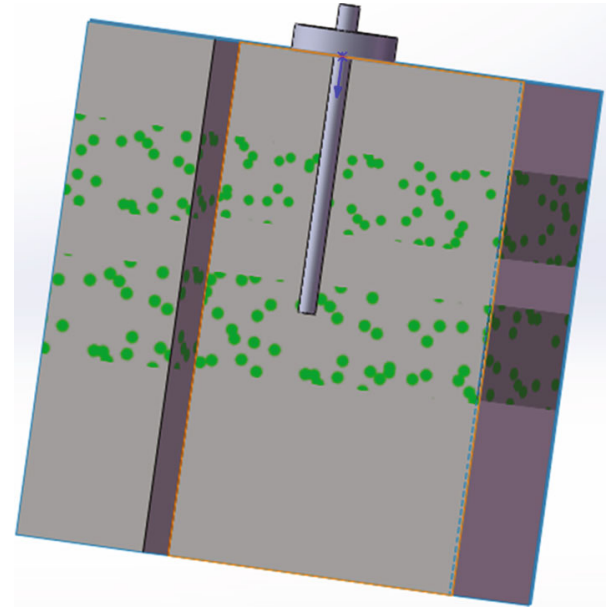

(b)

FIGURE 14: Vug strip in experiment 3: (a) fracture surface picture; (b) schematic diagram of the relationship between vug strip and fracture. Compared with other parts of the fracture surface, the vug strips have more fracturing fluid flow, and the wall absorbs more tracer.

for high Gaussian curvature and rougher surface and blue for low Gaussian curvature and smoother surface. The result is shown in Figure 17. The etching of the fracture surface by the acid solution was uneven, so that the red spot areas where the Gaussian curvature suddenly increased were distributed unevenly on the image. The analysis of the image showed that the roughness of the continuous vug region on the right of and below the wellbore was significantly higher than that in the left region. It matched the observation that the steering acid mainly corroded the fracture on the right of and below the well. The result is the same as that of previous studies [16].

Similarly, other results are shown in Figure 18. According to the above data processing flow, red spots represented rough surfaces where Gaussian curvature is large, and the blue spot was opposite. In the experimental results, there were red spot concentrated areas on the fracture surface, indicating that the surface was subjected to uneven etching of acid. In the results of experiment \#2 and \#4, the red spots on the surface of the fracture were evenly distributed. In 


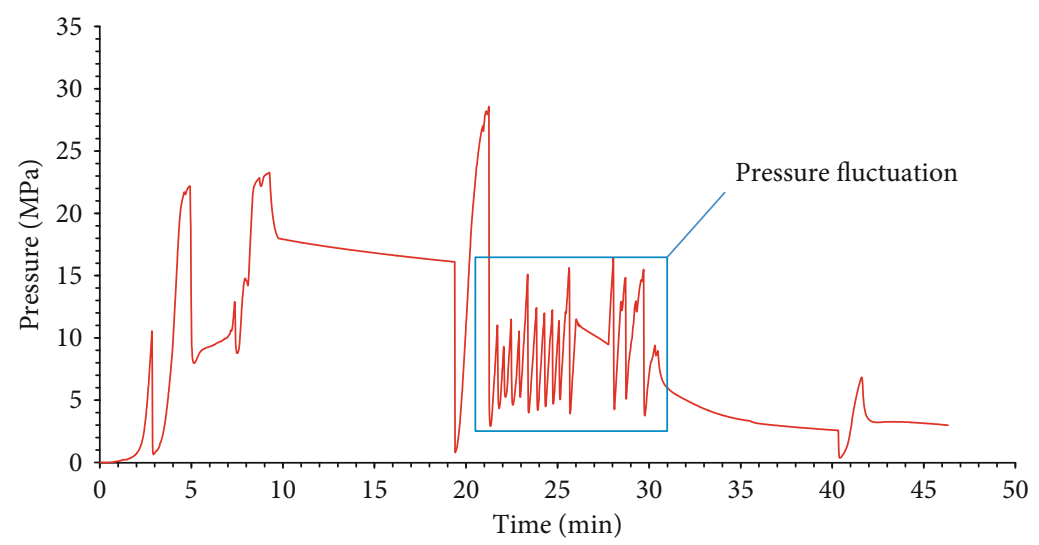

FIGURE 15: Pressure fluctuation in experiment 3.

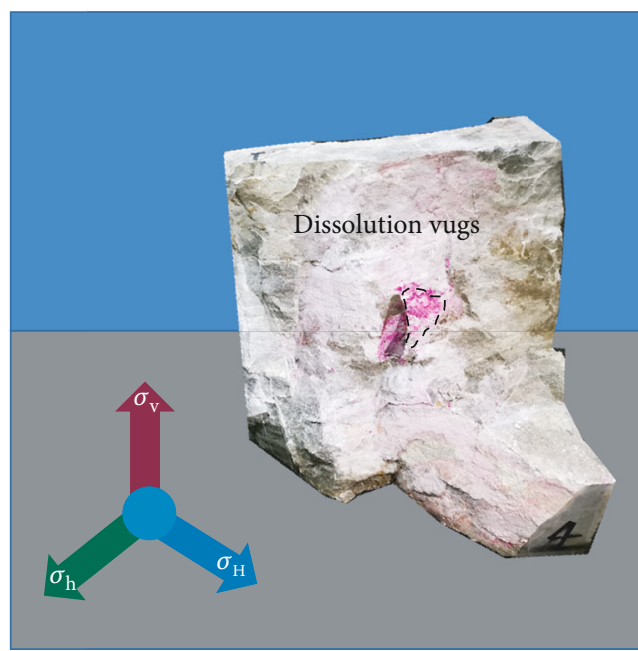

(a)

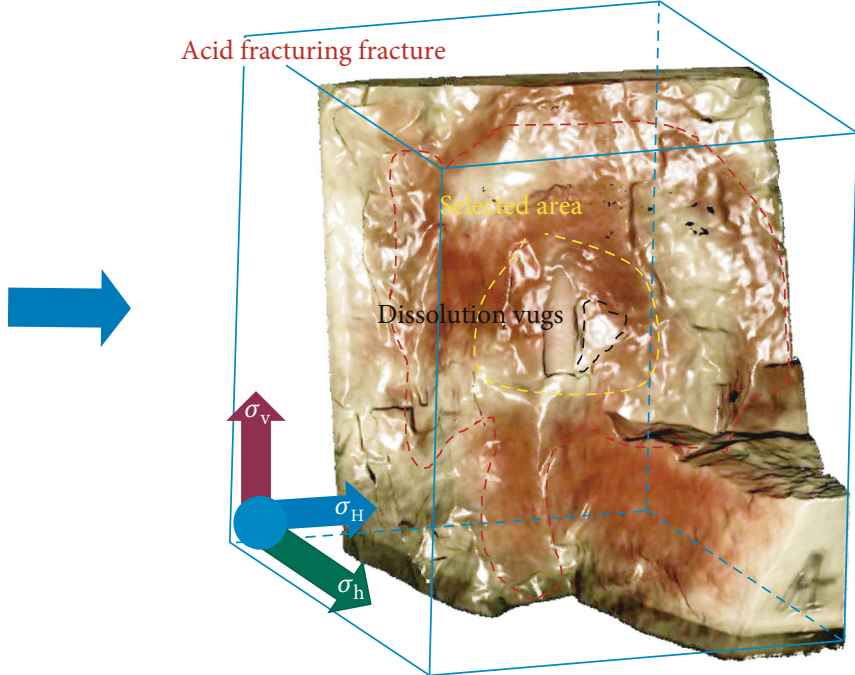

(b)

FIgURE 16: Experiment 1 fracture surface: (a) fracture surface; (b) 3D scanning result. Select a certain area including the dissolution vugs on the scanning result for subsequent processing.

particular, there was no concentrated area of red spots in experiment \#4. The blue part of the fracture surface of experiment \#2 was the largest, and the red part of experiment 4 was the largest.

The roughness of the fracture surface is affected by two factors: internal vugs and acid corrosion. The results in Figure 18 were analyzed. Experiment \#2 used a matrix-type carbonate rock, which was characterized by weak heterogeneity and less fracture vug structure. Therefore, compared with other results, the fracture surface roughness was low, and the acid-etching effect was uniform. Experiment \#3 and \#4 used fracture-vug carbonate rock. Different kinds of ahead fluid were used to cooperate with the steering acid. The results of experiment \#3 showed that the high viscosity ahead fluid would result in uneven etching of the fracture surface. In experiment \#4, the self-generating acid can react with the carbonate rock alone, so that the roughness of the fracture surface was the largest among all the experimental results. However, there was no uneven etching phenomenon observed. Based on the above results, self-generating acid as the ahead fluid is observed to have the best effect on fracture surface modification, and a low viscosity ahead fluid is recommended to form a uniform-etched fracture surface.

\section{Discussion}

In this paper, four acid fracturing experiments were carried out. The different ahead fluids and different kinds of rock are used to analyze fracture propagation in steering acid fracturing. It has been found that the results of acid fracturing are best when the steering acid is mixed with the low viscosity ahead fluid. This is probably because the low-viscosity ahead fluid easily penetrates the small fractures or vugs in the reservoir. Therefore, the low-viscosity ahead fluid is more likely to penetrate the small fractures in the reservoir, so that a bedding plane of the deep carbonate reservoir can be activated. Subsequent steering acid can fully react with the fracture surface and seal the reservoir after penetrating a certain distance, 


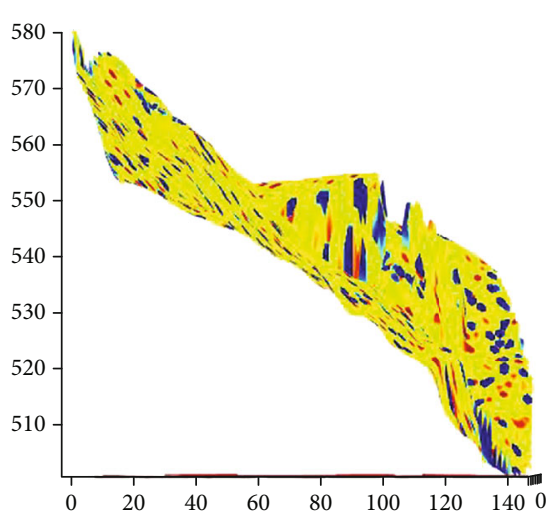

(a)

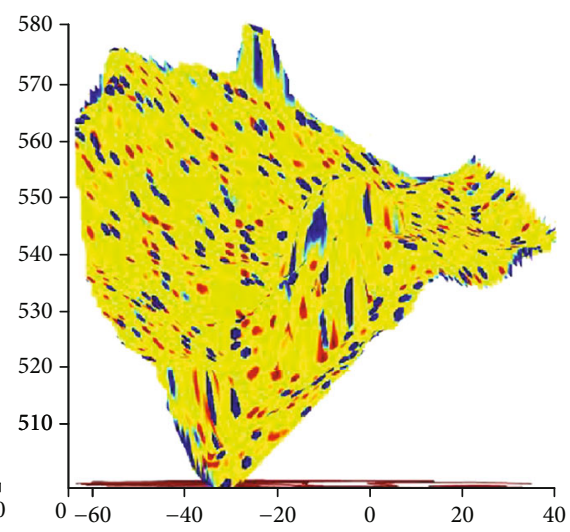

(b)

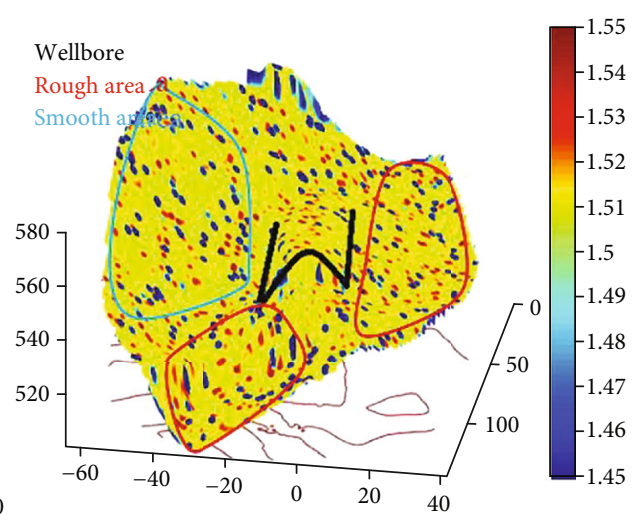

(c)

FIGURE 17: Gaussian curvature of the selected area: (a) left view; (b) front view; (c) stereogram. There are more red spots in the red area, indicating that the area has higher Gaussian curvature and a rougher surface. There are more blue spots in the blue area, indicating that the area has a lower Gaussian curvature and a smoother surface.

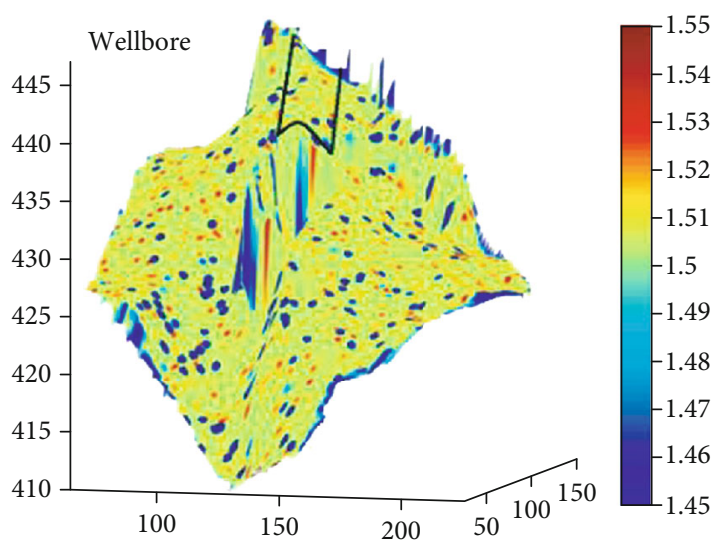

(a)

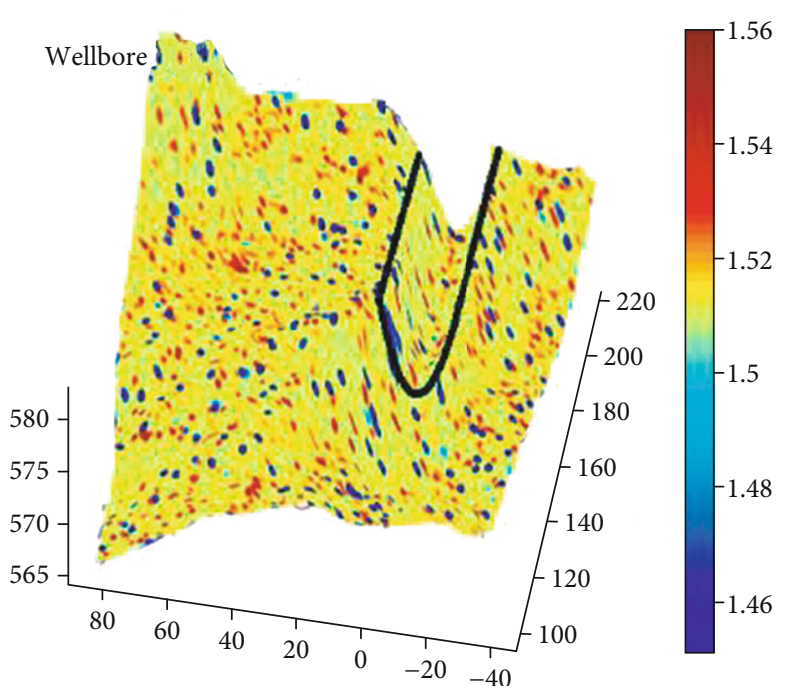

(b)

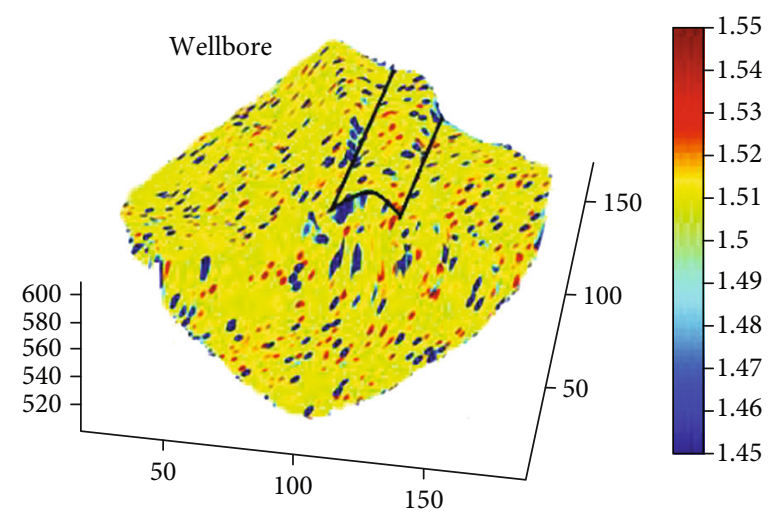

(c)

FIGURE 18: Gaussian curvature of fracture surface: (a) experiment 2 fracture surface; (b) experiment 3 fracture surface; (c) experiment 4 fracture surface. 
causing the subsequent fracturing fluid to enter other weak planes and open multiple fractures. If the viscosity of ahead fluid is too high, the effect of steering acid on promoting fracture complexity is not significant. If the ahead fluid is not used, the steering acid can only react to the reservoir near well bottom.

Based on the results of laboratory experiments, the workflow of on-site fracturing operation can be guided and improved to create a more complex fracture network in the target reservoir, which provides better fracturing efficiency. It can also reduce fracture initiation pressure. This conclusion supports the results of previous studies [17-19]. In field fracturing operation, if steering acid is injected directly into the wellbore, it will quickly react with carbonate rocks in the formation. Eventually, the acid could not reach distant natural fractures and fracturing efficiency will be unsatisfactory. Therefore, low-viscosity ahead fluid, such as slick water, can be regarded as a better choice. With the help of ahead fluid, steering acid can reach further distance to improve fracturing efficiency.

However, due to experiment limitations, there is no corresponding visual experiment [20-22]. Therefore, no microscopic understanding is obtained about the role of steering acid in the interior of the rock. In addition, the pressure fluctuation during fracturing is related to the injected liquid amount and fracture volume. The pressure fluctuation caused by the acid-rock reaction is determined by the absolute volume change. When the volume increases, the pressure fluctuation will create additional pressure decrease. Otherwise, the treatment pressure will increase. Subsequent research can be conducted along this direction, so that the fracture volume and the decrease degree of the fracture initiation pressure can be evaluated according to the pressure fluctuation.

\section{Conclusions}

In this study, the carbonate rocks from Sichuan, China, were used for laboratory large-scale triaxial acid fracturing experiments to study the fracture initiation and propagation of steering acid fracturing in carbonate reservoir. Different ahead fluids were used for comparative experiments. Fracturing fluids in this study were slick water, self-generating acid, and the gel. They were made according to the field application formula. The $3 \mathrm{D}$ scanning technique was used to obtain the fracture surfaces roughness and helps to analyze the results. The final conclusions are as follows:

(1) When low-viscosity ahead fluid is used with steering acid or steering acid is used directly for acid fracturing, it is easy for fracture to change propagation direction under the influence of the natural fractures and vugs and form complex fracture network. When high-viscosity ahead fluid is used, the possibility to change fracture propagation direction decreases, with small influence from the natural fracture structure of the reservoir

(2) Natural fractures influence the propagation of acidetched fracture. Natural vugs affect the penetrating direction of fracturing fluid to influence acid-etched fracture. The specimen with more vugs has large leak-off rate of the fracturing fluid

(3) The acid will corrode the carbonate rock, which results in a larger roughness of fracture surface. Low-viscosity ahead fluid will cause the acid to evenly etching fracture surfaces, while high-viscosity ahead fluid will act the opposite. When the self-generated acid is used as the ahead fluid, the fracture surface roughness is the largest and there is no uneven etching phenomenon

\section{Data Availability}

The underlying data and figures can be found in the manuscript.

\section{Conflicts of Interest}

The authors declare that they have no conflicts of interest.

\section{Acknowledgments}

The authors are grateful for the Project Support of NSFC (No. 52074311, No. 51874328, No. U19B6003-05) and the Strategic Cooperation Technology Projects of CNPC and CUPB (ZLZX2020-02).

\section{References}

[1] H. Bing, C. Diao, and D. Li, "An experimental investigation of geomechanical properties of deep tight gas reservoirs," Journal of Natural Gas Science \& Engineering, vol. 47, pp. 22-33, 2017.

[2] H. Bing, R. Zhang, T. Peng et al., "Characteristics of fracture propagation in compact limestone reservoir by hydraulic fracturing in central Sichuan, China," Journal of Natural Gas Science \& Engineering, vol. 57, pp. 122-134, 2018.

[3] Y. Lu, L. Zeng, Q. Xie, Y. Jin, M. M. Hossain, and A. Saeedi, "Analytical modelling of wettability alteration-induced micro-fractures during hydraulic fracturing in tight oil reservoirs," Fuel, vol. 249, pp. 434-440, 2019.

[4] Y. Wang, Q. Yuan, and L. I. Li, "Deep penetrating acid fracturing involving self-generated acid in carbonate reservoirs of the Tahe Oilfield," Petroleum Drilling Techniques, vol. 44, no. 5, pp. 90-93, 2016.

[5] Z. Fengshou, W. Jianfa, H. Haoyong et al., "Technological parameter optimization for improving the complexity of hydraulic fractures in deep shale reservoirs," Natural Gas Industry, vol. 41, no. 1, pp. 125-135, 2021.

[6] K. Aldhayee, M. T. Ali, and H. A. Nasr-El-Din, "Acid wormholing in multistage acid fractured wells completed in tight naturally fractured dolomite reservoir: benefits and impacts on acid fracturing stimulation design," in SPE International Hydraulic Fracturing Technology Conference and Exhibition, 2018.

[7] M. J. Economides and K. G. Nolte, Reservoir Stimulation, no. 6, 1989Prentice Hall Inc, Old Tappan, NJ, 1989.

[8] B. Hou, R. Zhang, M. Chen, J. Kao, and X. Liu, "Investigation on acid fracturing treatment in limestone formation based on true tri-axial experiment," Fuel, vol. 235, pp. 473-484, 2019. 
[9] B. R. Lungwitz, C. N. Fredd, M. E. Brady, M. J. Miller, S. A. Ali, and K. N. Hughes, "Diversion and cleanup studies of viscoelastic surfactant-based self-diverting acid," SPE Production \& Operations, vol. 22, no. 1, pp. 121-127, 2007.

[10] A. M. Gomaa, A. Nino-Penaloza, J. Cutler, and S. Chaudhary, "Insights of wormhole propagation during carbonate acidizing: constant pressure vs. constant rate," in Spe Technical Conference and Exhibition, Houston, TX, USA, 2015.

[11] M. Chen, F. Pang, and Y. Jin, "Simulation and analysis of real triaxial hydraulic fracturing," Chinese journal of rock mechanics and Engineering, no. S1, pp. 868-872, 2000.

[12] B. Hou, Z. Chang, W. Fu, Y. Muhadasi, and M. Chen, "Fracture initiation and propagation in a deep shale gas reservoir subject to an alternating-fluid-injection hydraulic-fracturing treatment," Society of Petroleum Engineers, vol. 24, no. 4, pp. 1839-1855, 2019.

[13] A. Alameri and T. Gamadi, "Optimization of acid fracturing for a tight carbonate reservoir," Petroleum, vol. 6, no. 1, pp. 70-79, 2020.

[14] Z. Liu, M. Chen, and G. Zhang, "Analysis of the influence of a natural fracture network on hydraulic fracture propagation in carbonate formations," Rock Mechanics \& Rock Engineering, vol. 47, no. 2, pp. 575-587, 2014.

[15] W. Cheng, Y. Jin, M. Chen, T. Xu, Y. Zhang, and C. Diao, “A criterion for identifying hydraulic fractures crossing natural fractures in 3D space," Petroleum Exploration and Development, vol. 41, no. 3, pp. 371-376, 2014.

[16] G. Bo, L. Xiao, H. Ma, and Z. H. O. U. Changlin, "Influence of hydraulic fracture morphology on acid etching behavior and conductivity," Journal of Southwest Petroleum University, vol. 41, no. 3, pp. 80-90, 2019.

[17] H. A. Nasr-El-Din, S. M. Al-Driweesh, A. S. Metcalf, and J. B. Chesson, "Fracture acidizing: what role does reservoir softening play in production response?," SPE Production \& Operations, vol. 17, no. 23, pp. 31-67, 2008.

[18] Z. Luo, L. Fei, P. Liu, N. Li, and Y. Gong, "A model and interpretation method of pressure decline for acid fracturing," in 2012 International Conference on Computational ProblemSolving (ICCP), pp. 236-241, Leshan, China, October 2012.

[19] F. Hou, X. Y, A. I. Zhang, and J. I. N. G. LV, "Research and application of self-generating acid in deeply penetrating acid fracturing for ultra-deep and high temperature carbonate reservoir (in Chinese)," Drilling \& Production Technology, vol. 41, no. 1, pp. 35-37, 2018.

[20] H. Bing, R. Zhang, Y. Zeng, W. Fu, Y. Muhadasi, and M. Chen, "Analysis of hydraulic fracture initiation and propagation in deep shale reservoir with high horizontal stress difference," Journal of Petroleum Science \& Engineering, vol. 170, pp. 231-243, 2018.

[21] J. Mou, D. Zhu, and A. D. Hill, “Acid-etched channels in heterogeneous carbonates - a newly discovered mechanism for creating acid fracture conductivity," SPE Journal, vol. 15, no. 2, pp. 404-416, 2010.

[22] R. M. Rahman, O. O. Awoleke, and S. D. Goddard, "Metaanalysis of propped fracture conductivity data-fixed effects regression modeling," Journal of Petroleum Science and Engineering, vol. 182, p. 106280, 2019. 